\title{
OBITUARY
}

\section{In memoriam: Sheldon Rosenberg, Founding Editor}

\author{
LEONARD ABBEDUTO \\ MIND Institute
}

\begin{abstract}
ADDRESS FOR CORRESPONDENCE
Leonard Abbeduto, MIND Institute, and Department of Psychiatry and Behavioral Sciences, University of California, Davis, School of Medicine, 2825 50th Street, Sacramento, CA 95817.

E-mail: leonard.abbeduto@ucdmc.ucdavis.edu
\end{abstract}

Sheldon Rosenberg, the Founding Editor of Applied Psycholinguistics, died on October 9, 2012, in Evanston, Illinois, as a result of complications from Parkinson disease. He was 82.

Dr. Rosenberg was born in New York City in 1930. He earned a bachelor's degree from Brooklyn College in 1954 and completed his $\mathrm{PhD}$ in psychology at the University of Minnesota in 1958, where he worked with the well-known psycholinguist James Jenkins. Dr. Rosenberg held research faculty positions at the Training School at Vineland (1959-1961), the George Peabody College for Teachers in Nashville (1961-1966), and the Center for Research on Language and Language Behavior at the University of Michigan (1966-1969). He began a faculty position in the Department of Psychology at the University of Illinois at Chicago (UIC) in 1969, teaching and mentoring graduate students in the department's developmental and cognitive program areas. He retired from the faculty in 1995.

Dr. Rosenberg's early research focused on the ways in which the semantic contextual features of words affected their integration into a coherent semantic representation during sentence comprehension, production, and recall. This line of inquiry began with a painstaking construction of a set of norms (Rosenberg \& Koen, 1968) based on adult judgments about the extent to which various sentences conveyed propositions reflecting common, canonical events (e.g., "the dog chased the cat") or possible, but less likely to occur, events (e.g., "the dog scared the goat"). $\mathrm{He}$ and his colleagues then traced the developmental emergence of the sensitivity to this propositional variation in semantic integration in comprehension, memory, and language production from childhood into adulthood (e.g., Rosenberg, 1968, 1969; Rosenberg \& Jarvella, 1970; Rosenberg, Jarvella, \& Cross, 1971). This approach to language ascribed an important role for local dependencies between words and to experience and thus, foreshadowed elements of emergentist accounts of language learning and current research focused on young children's sensitivity to statistical regularities in their linguistic input.

(C) Cambridge University Press 2013 0142-7164/13 \$15.00 
A second line of research focused on individuals with language impairments, especially those with intellectual disabilities. Included were studies of pragmatic and syntactic deficits (Abbeduto \& Rosenberg, 1980; Rosenberg \& Abbeduto, 1987), which led to a metric for scoring complex sentences in terms of order of developmental emergence that has been used to study impairments in a variety of populations, including the elderly. Numerous chapters in edited volumes and a monograph also emerged from this work (Rosenberg \& Abbeduto, 1993).

Arguably, however, Dr. Rosenberg's most important and lasting contribution to the field is Applied Psycholinguistics. Although the first issue of the Journal appeared in 1980, Dr. Rosenberg worked tirelessly for much of the decade of the 1970 s to develop the concept, identify a publisher, convene an impressive editorial board, and develop a format. He envisioned the journal as an outlet for hypothesisdriven research that extended cutting-edge research and theory in experimental psycholinguistics and language acquisition to applied problems. He saw the scope as including language disorders, reading, writing, bilingualism, second-language learning and instruction, and computer-based speech and language processing. Applied Psycholinguistics continues to thrive even in its fourth decade, with nearly 1,000 articles and reviews published to date. This success is evidence of Dr. Rosenberg's unique vision and enduring impact on the field.

Dr. Rosenberg was a skilled and compassionate mentor. He had extremely high standards for his students, but he also provided the support to make them successful and always treated them with respect, making them feel like colleagues rather than novices. In my case, I entered graduate school underprepared for the challenge. Dr. Rosenberg somehow managed to give me a chance and always championed my cause. He also knew when to push and when to give a pat on the back. I owe any professional success I have had to him.

Sheldon Rosenberg also had a lasting impact on every person he met. He had a booming voice and a hearty laugh, and no one told a joke with as much energy and enjoyment as he did. He also took great pride in his family. Whenever he spoke about his wife, Irma, or his sons, Eric and Jason, one immediately sensed his deep love for them and the joy they gave him. His daughters-in-law, Miriam and Sheila, and grandsons, Gordon, Clarke, and Graham, added greatly to his joy. Sheldon Rosenberg was one of those rare people who is able to balance a complete commitment to his profession with a complete devotion to his family. He enjoyed his life and gave great happiness to others. He will be missed greatly by many.

\section{REFERENCES}

Abbeduto, L., \& Rosenberg, S. (1980). The communicative competence of mildly retarded adults. Applied Psycholinguistics, 1, 405-426.

Rosenberg, S. (1968). Association and phrase structure in sentence recall. Journal of Verbal Learning and Verbal Behavior, 7, 1077-1081.

Rosenberg, S. (1969). The recall of verbal material accompanying semantically well-integrated and semantically poorly-integrated sentences. Journal of Verbal Learning and Verbal Behavior, 8, $732-736$.

Rosenberg, S., \& Abbeduto, L. (1987). Peer group conversational indicators of linguistic competence in mildly retarded adults. Applied Psycholinguistics, 8, 19-32. 
Rosenberg, S., \& Abbeduto, L. (1993). Language and communication in mental retardation: Development, processes, and intervention. Hillsdale, NJ: Erlbaum.

Rosenberg, S., \& Jarvella, R. J. (1970). Semantic integration and sentence perception. Journal of Verbal Learning and Verbal Behavior, 9, 548-553.

Rosenberg, S., Jarvella, R. J., \& Cross, M. (1971). Semantic integration, age, and the recall of sentences. Child Development, 42, 1959-1966.

Rosenberg, S., \& Koen, M. J. (1968). Norms of sequential associative dependencies in active declarative sentences. In J. C. Catford (Ed.), Studies in language and language behavior, supplement to Progress Report VI. Ann Arbor, MI: University of Michigan, Center for Research on Language and Language Behavior. 